\title{
Ultra-short cementless anatomical stem for intracapsular femoral neck fractures in patients younger than 60 years
}

\author{
Marian MelisiK, Maros Hrubina, Matej Daniel, Zoltan Cibula, Marek RovnaK, Libor Necas \\ From the Jessenius Faculty of Medicine in Martin, Comenius University in Bratislava, Martin, Slovak Republic
}

The aim of this study was to present the midterm results of total hip arthroplasty with ultra-short anatomical cementless stem in the primary treatment of displaced intracapsular femoral neck fractures in patients younger 60 years.

From 2006 to 2015, 17 hip arthroplasties (with the Proxima stem) were performed in group of 17 patients for the treatment of acute femoral neck fractures Garden type III and IV. The mean follow-up period was 112.7 (range: 64-148) months. Patients were evaluated retrospectively - clinically and radiographically, using the Harris hip scoring system during the year 2020. Seven males and ten females (mean age: $\mathbf{4 5 . 0}$ years) were included in the study. Each of them had one or more risk factors (time delay, comminution of the femoral neck, corticosteroids usage, the presence of coxarthrosis, rheumatoid arthritis, alcohol abuse, etc...), because of which the osteosynthesis was not performed. Harris hip scores were 6.3 preoperatively and 82.9 at the final follow-up.

Three patients (17.6\%) had complications: luxation, aseptic stem loosening (migration with subsidence "varisation" and thigh pain) and deep infection. One patient $(5.9 \%)$ with infection was revised.

In carefully selected younger patients with displaced intracapsular femoral neck fracture, where the osteosynthesis as first treatment option should be associated with high risk of complication (avascular femoral head necrosis, non-union) due to the presence of risk factors, the primary total hip arthroplasty could be performed. The ultra-short cementless stem offers promising results in these rare cases in the midterm.

The authors stated that there are no conflicts of interest regarding the publication of this article.
Keywords: total hip arthroplasty; femoral neck fracture; ultra-short anatomical cementless stem.

\section{INTRODUCTION}

Displaced intracapsular femoral neck fractures of Garden types III and IV (DIFNF) in younger patients (under 60 years) remain associated with a relatively high incidence of non-union, femoral head necrosis and other complications, which may lead to revision surgery after a primary

\footnotetext{
Marian Melisik ${ }^{1,2}, \mathrm{MD}$

Maros Hrubina ${ }^{1,2}, \mathrm{MD}, \mathrm{PhD}$

Matej Daniel ${ }^{3}$, prof, RNDr, PhD

Zoltan Cibula ${ }^{1,2}, \mathrm{MD}, \mathrm{PhD}$

Marek Rovnak ${ }^{1,2}, \mathrm{MD}$

- Libor Necas ${ }^{1,2}, \mathrm{MD}, \mathrm{PhD}$

'Jessenius Faculty of Medicine in Martin, Comenius University in Bratislava, Martin, Slovak Republic.

${ }^{2}$ University Department of Orthopaedic Surgery, University

Hospital Martin, Kollarova 2, Martin, 036 59, Slovak

Republic.

${ }^{3}$ Department of Mechanics, Biomechanics and Mechatronics, Faculty of Mechanical Engineering, Czech Technical University in Prague, Technicka 4, Prague 6, 166 07, Czech Republic.

Correspondence : Libor Necas, University Department of Orthopaedic Surgery, University Hospital Martin, Kollarova 2, Martin, 036 59, Slovak Republic.

Email : necas@unm.sk

- 2021, Acta Orthopædica Belgica.
} 
osteosynthesis, which has been recommended as a first-line treatment option $(6,15,23)$. The aim of osteosynthesis is to restore the native hip joint anatomy and biomechanics, using one of a variety of different devices (sliding hip screw, multiple cancellous screws, etc.). The published risk factors for failure of such surgery are: time delay, femoral neck comminution, corticosteroids, degenerative changes in the hip and others (alcohol dependence, osteoporosis, rheumatoid arthritis, chronic kidney disease) $(3,20,27)$. Total hip arthroplasty (THA) is a treatment option for DIFNF in patients above 70 years and is indicated to treat failed proximal femoral osteosynthesis. Despite this fact, the question arises what to do with a relatively young patient with DIFNF, with significant risk factors for failure of primary osteosynthesis. Should we perform the osteosynthesis with a relative high risk of complications, which may lead to revision with THA, or decide on primary treatment with a THA? Rogmark et al. reported that, specific non-elderly patients are candidates for a primary THA (21). Because bone-saving arthroplasty is a reasonable option for younger patients, we decided to use an ultra-short cementless stem in these specific cases $(7,13)$. The aim of this study was to evaluate clinically and radiographically this series of young patients who had undergone primary THA with a Proxima stem for the treatment of DIFNF.

\section{MATERIALS AND METHODS}

This is a retrospective cohort study. Patient records were reviewed retrospectively for demographic data, details of operation and follow-up results.

The study group consisted of 17 patients with DIFNF of Garden types III and IV, who were treated with primary THA (using the Proxima stem) between 2006 and 2015.

Included in this study were 17 hips of seven males and 10 females (mean age: 45.0; range: 25-60 years), who each completed a minimum follow-up of five years. In these patients, osteosynthesis was considered to be contraindicated due to the presence of specific risk factors (time delay of 48 hours or more, posterior comminution of the femoral neck, or comminution of more than $25 \%$ of the neck diameter according to the CT scan, corticosteroids, coxarthrosis grade II.-III. according to Kellegren and Lawrence's classification, and others (alcohol dependence, rheumatoid arthritis, osteoporosis, chronic kidney disease) (11).

Previously operated hips, inflammatory or oncologic diseases in the area of the operated hip joint, or patients with incomplete follow-up were excluded.

Preoperative planning and templating on radiographs were used to determine the implant sizes. All procedures were performed by two experienced surgeons (L.N., M.M.) in the supine position through an antero-lateral approach. A cementless Pinnacle cup (DePuy, Warsaw, IN, USA), (range: 52-62mm) was implanted with an inclination of $40^{\circ}-45^{\circ}$ and $15^{\circ}$ of anteversion, using a press-fit technique. The ceramic inlay was inserted. Next the Proxima stem (DePuy, Leeds, UK) was inserted with the use of a „round the corner" technique. We used a standard stem 15 times and high-offset stem twice; the most frequently used stem size was 5 (graph 1). A 36mm ceramic head was used in every case.

Drains were removed, and both active and passive movements started on the first postoperative day. Patients were discharged from seven days postoperatively (range: 7-12). Walking, touchweightbearing with crutches, was recommended until six weeks postoperatively, when patients were examined clinically and radiologically; thereafter partial weightbearing was permitted. After the next clinical and radiological examination at the third month, full weight-bearing was allowed.

All patients were examined clinically and radiologically at six weeks, three and six months, one year and then annually thereafter until the year 2020 .

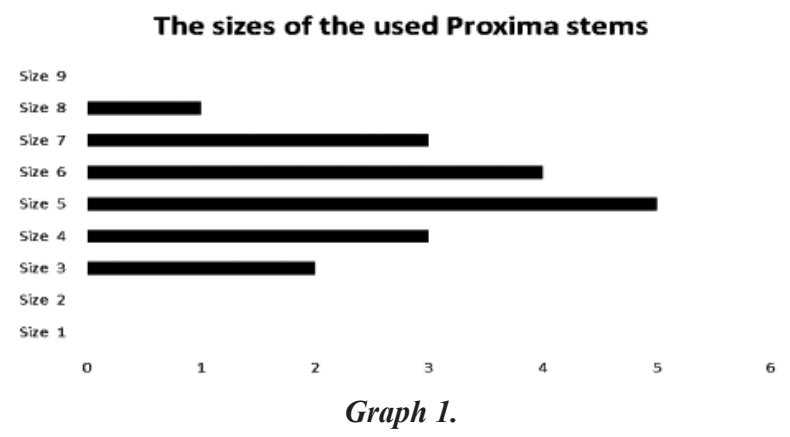




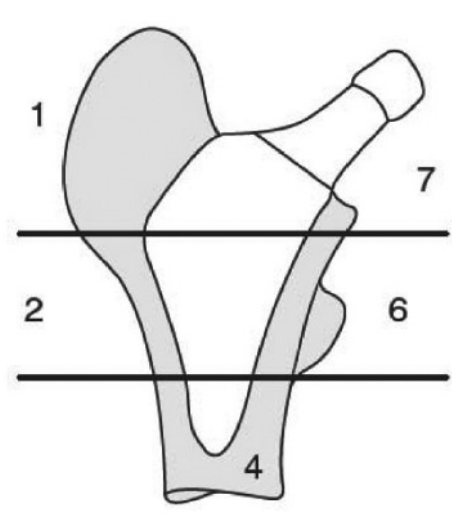

Fig. 1 - Modified Gruen zones for the ultra-short cementless Proxima stem, without "classic zones" 3 and 5.
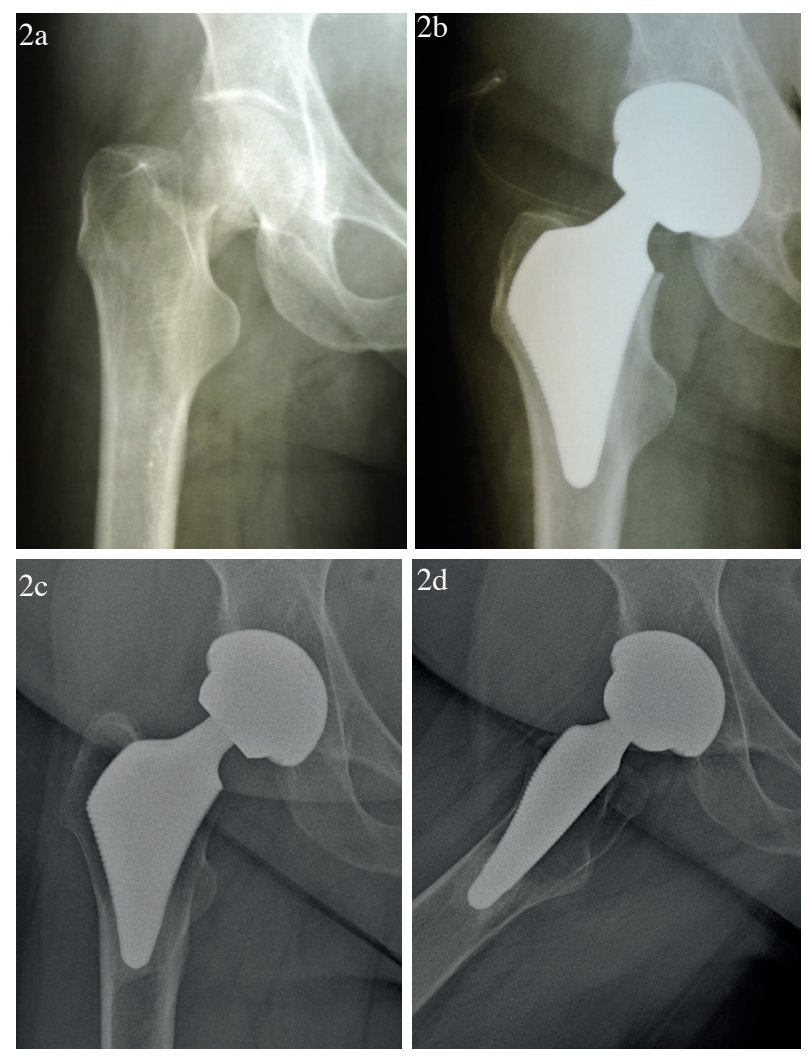

Fig. 2. - a Anteroposterior radiograph of 54-years old patient with a displaced intracapsular femoral neck fracture Garden type III, indicated for primary total hip arthroplasty. $\boldsymbol{b}$ Radiograph of the same patient on the first day after the cementless total hip arthroplasty, with the correct size of the Proxima stem in a neutral position. $c$ Anteroposterior radiograph of the same patient, 11 years postoperatively, osseously stable stem fixation with bony trabecular development around the apex of the stem and stress-shielding phenomenon grade I in modified Gruen zone 7. $\boldsymbol{d}$ Axial radiograph with bony trabecular development around the apex of the stem.
Basic demographic data were collected, including: age, body mass index (BMI), affected side, risk factors.

The clinical status of the patients was documented using the Harris hip score (HHS) (8). Thigh pain was recorded.

The leg length discrepancy (LLD) was measured radiologically.

We recorded early and late complications and any need for reoperation.

Pre- and postoperative radiographs (anteroposterior and lateral) were examined blindly by an experienced orthopaedic radiologist. On the preoperative radiographs, we assessed the type of the fracture. On the initial postoperative radiographs we evaluated the cup position and stem alignment - which was rated as normal, if its deviation from the axis of the femoral shaft was $5^{\circ}$ or less. A deviation (malalignment) of $6^{\circ}-10^{\circ}$ was rated as varus or valgus, and a deviation exceeding $10^{\circ}$ was rated as severe varus or severe valgus (7). Radiological examination during the next follow-up focused on: stem subsidence, migration, loosening, osteolysis, proximal stress shielding,and bony trabecular development in modified Gruen zones for the Proxima stem (fig. 1, 2a-d) (18). Implant migration was evaluated according to Martel et al. (17). Implant stability was assessed according to Engh et al., based on the radiological features of the bone-implant interface (5). Criteria for radiological loosening of the stem were defined as a radiolucent zone greater than $2 \mathrm{~mm}$, or a migration greater than $2 \mathrm{~mm}$ with an adjacent radiolucent zone $(7,14)$.

Stress-shielding phenomenon was assessed according to Zicat et al. (28). Heterotopic ossification was evaluated using the Brooker's classification (1).

The clinical and radiological evaluations were all performed by the same surgeon (M.H.), who did not perform any of the surgical procedures.

Two-sided, paired Student's $t$-test was used for statistical analysis of the pre- and postoperative Harris hip scores. Statistical differences were considered to be signifiant when the $p$ value was $<0.05$. A power analysis, using the R 3.5.0 (R Core Team, 2018), power package, indicated that a total sample of 15 patients (hips) would be needed to detect large effects $(\mathrm{d}=0.8)$ with $80 \%$ power, using a two- 
Table 1. - Patients' demographic and risk factors for the osteosynthesis failure

\begin{tabular}{|c|c|c|c|c|c|c|c|c|}
\hline $\begin{array}{l}\text { Patient } \\
\text { No. }\end{array}$ & $\begin{array}{c}\text { Age } \\
\text { (years) }\end{array}$ & $\begin{array}{l}\text { Body mass } \\
\text { index (BMI) }\end{array}$ & Side & \begin{tabular}{|c|} 
Time \\
delay \\
48 hours \\
and more \\
\end{tabular} & $\begin{array}{c}\text { Cominution } \\
\text { of the femoral } \\
\text { neck more than } \\
25 \% \\
\end{array}$ & $\begin{array}{c}\text { Cortico- } \\
\text { steriods } \\
\text { usage }\end{array}$ & Coxarthrosis & $\begin{array}{c}\text { Others (alcohol abuse, } \\
\text { rheumatoid arthritis } \\
\text { osteoporosis, chronice } \\
\text { kidney disease) }\end{array}$ \\
\hline 1. & 28 & 27,7 & $\mathrm{R}$ & yes & yes & no & no & yes \\
\hline 2. & 60 & 32,9 & $\mathrm{R}$ & yes & yes & no & yes (gr. II.-III. ) & no \\
\hline 3. & 25 & 23,4 & $\mathrm{~L}$ & yes & yes & yes & no & yes \\
\hline 4. & 38 & 22,6 & $\mathrm{~L}$ & yes & yes & no & no & no \\
\hline 5. & 60 & 28,7 & $\mathrm{~L}$ & yes & no & yes & no & no \\
\hline 6. & 46 & 26,4 & $\mathrm{R}$ & yes & yes & no & no & no \\
\hline 7. & 59 & 28,4 & $\mathrm{R}$ & Yes & no & no & yes (gr. III. ) & no \\
\hline 8. & 41 & 23,6 & $\mathrm{R}$ & yes & yes & no & no & no \\
\hline 9. & 27 & 23,8 & $\mathrm{~L}$ & no & yes & no & no & no \\
\hline 10. & 39 & 22,4 & $\mathrm{R}$ & yes & yes & no & no & yes \\
\hline 11. & 57 & 24,6 & $\mathrm{R}$ & yes & no & no & no & yes \\
\hline 12. & 54 & 27,7 & $\mathrm{~L}$ & yes & yes & no & no & no \\
\hline 13. & 28 & 22,4 & $\mathrm{R}$ & yes & yes & no & no & no \\
\hline 14. & 49 & 34,0 & $\mathrm{R}$ & yes & yes & yes & no & no \\
\hline 15. & 52 & 28,6 & $\mathrm{R}$ & yes & yes & no & no & yes \\
\hline 16. & 49 & 28,6 & $\mathrm{~L}$ & yes & no & yes & no & yes \\
\hline 17. & 54 & 30,0 & $\mathrm{R}$ & yes & no & yes & yes (gr. II.-III. ) & no \\
\hline
\end{tabular}

sided paired $t$-test between means with alpha at .05 (2).

All patients gave written informed consent for ultra-short anatomical cementless stem implantation before surgery, and all of them gave informed consent for inclusion into this study.

\section{RESULTS}

All 17 patients were followed and the final evaluations were performed during the year 2020 . The mean follow-up was 112.7 (range: 64-148 months).

The left hip was affected six times, and the right 11times. The mean BMI was 26.7; range: 22.4-34.0.

We recorded Garden type III fractures in seven cases $(41 \%)$ and type IV in 10 cases (59\%). Four patients were younger than 30 years (all with highenergy trauma: two due to car accidents, one a fall from a horse, one ice hockey injury). The mean HHSs significantly increased from 6.3 (range: 2 to 12) points preoperatively to 82.9 (range: 52 to 100 points) at the final follow-up ( $p=0.001)$. Finally, four patients $(23.5 \%)$ had excellent hip scores (range: 90 to 100 points), 10 patients (58.8\%) had good scores (range: 80 to 89 points), two patients $(11.8 \%$ ) had fair scores (range: 70 to 79 points) and one patient (5.9\%) had a poor score (less than 70 points).

All of our patients had one or more of the abovementioned risk factors for osteosynthesis failure (table 1).

LLD was $2.8 \mathrm{~cm}$ (average shortening of the affected extremity) before the operation (range: 1.5$4 \mathrm{~cm}$ ) and $0.5 \mathrm{~cm}$ (average elongation of the operated extremity) during final follow-up (range: $0-2 \mathrm{~cm}$ ).

The mean inclination angle of the cup was $44^{\circ}$ (range: $40-56^{\circ}$ ). We found no migration of the cup, or radiolucent lines around the cup.

Initial stem alignment was neutral in 16 patients $(94.1 \%)$ and varus (up to $\left.5^{\circ}\right)$ in one $(5.9 \%)$.

We found stem subsidence (migration) in three hips $(17.6 \%)$.

In one of these - implanted in a position of $5^{\circ}$ varus, migration was noted during the first six postoperative months. The subsidence was to $2 \mathrm{~mm}$, with progressive varus to $10^{\circ}$. At the next follow-up, this stem was osseously stable, without loosening or thigh pain. 

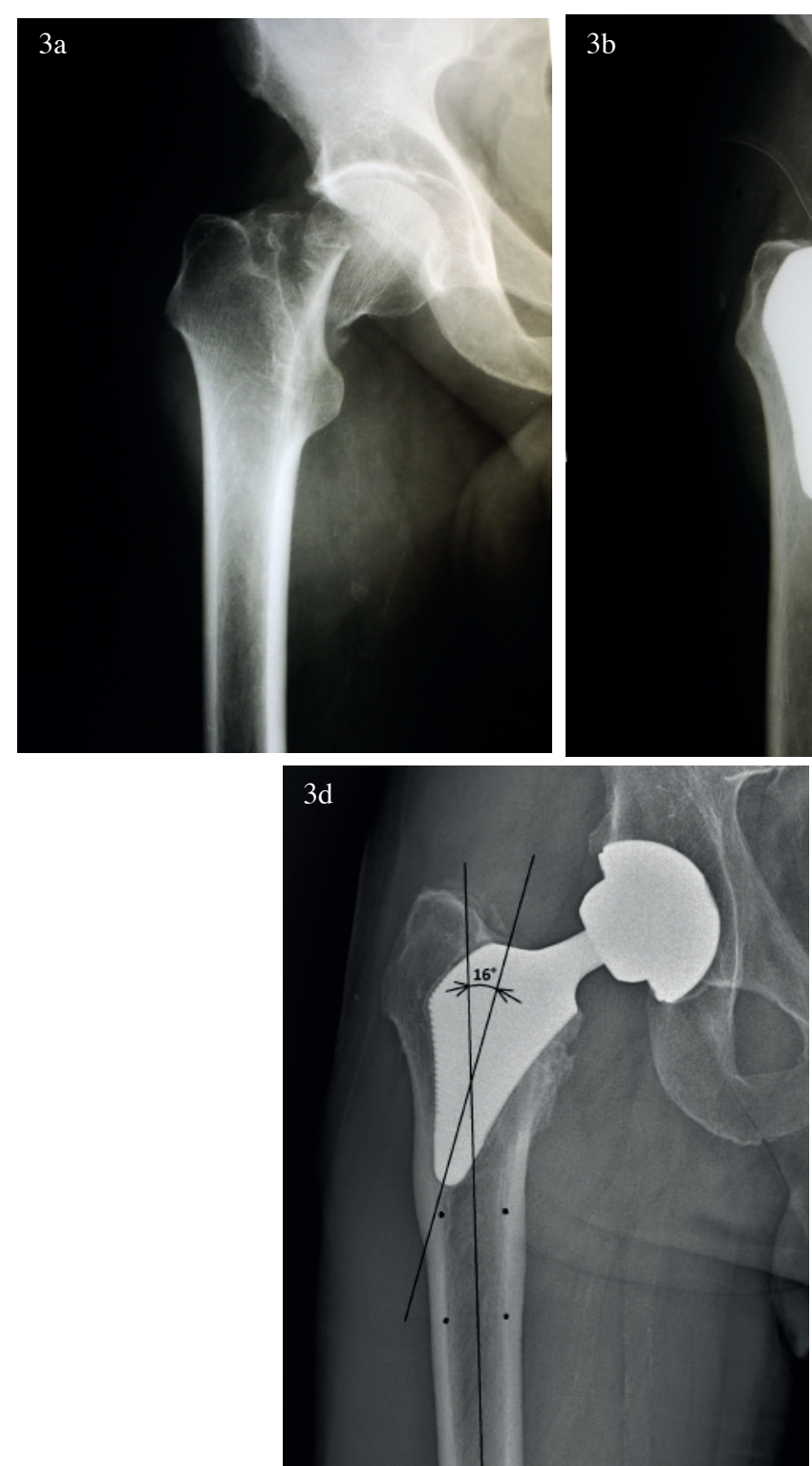
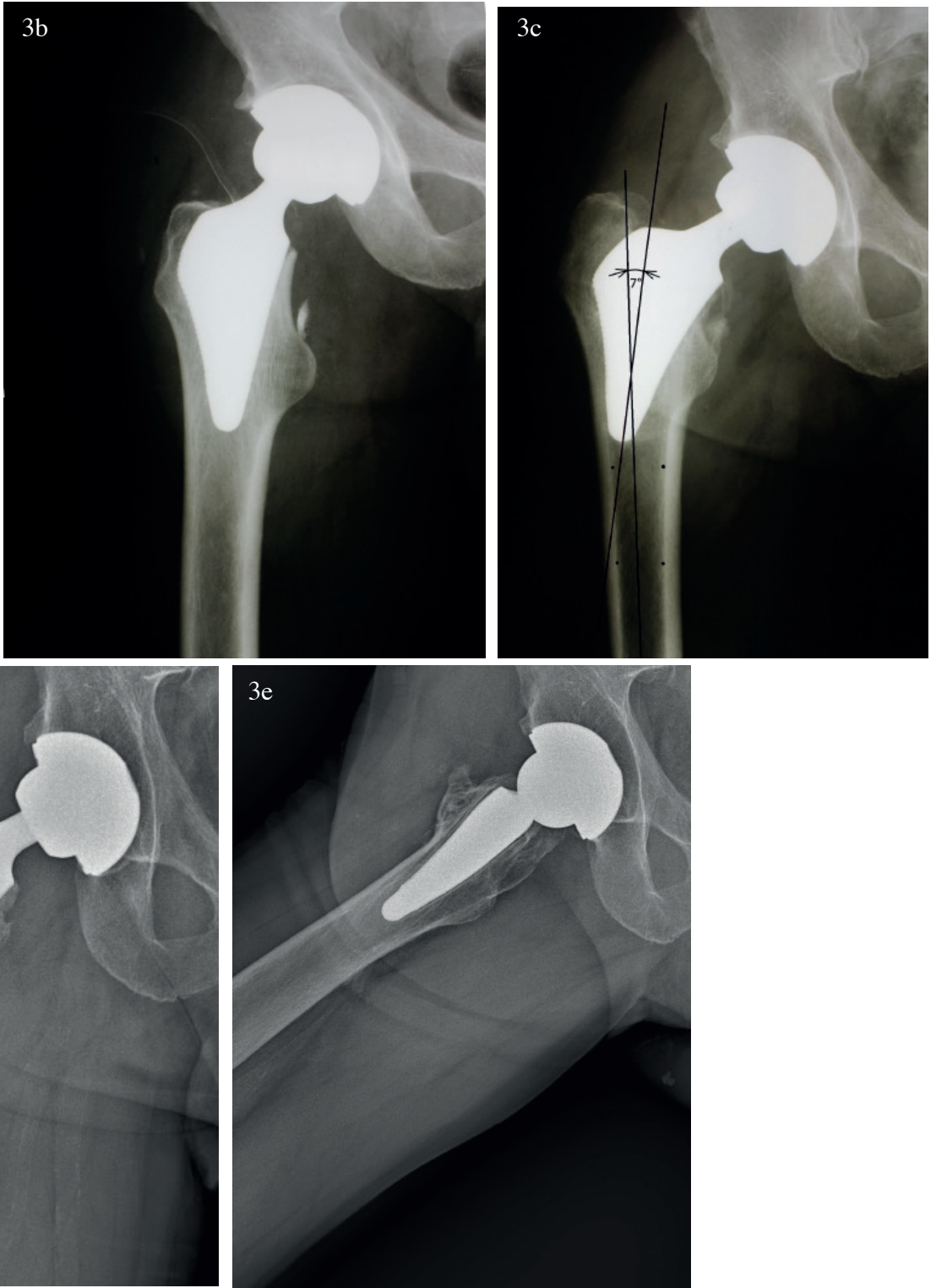

Fig. 3. - $\boldsymbol{a}$ Anteroposterior radiograph of 47-years old patient with a displaced intracapsular femoral neck fracture Garden type IV, indicated for primary total hip arthroplasty. $\boldsymbol{b}$ Radiograph of the same patient on the first postoperative day, the Proxima stem is in neutral position with possible undersizing (size 7). $c$ Anteroposterior radiograph of the same patient at the $3^{\text {rd }}$ postoperative month, with visible early subsidence and stem migration (varisation to $7^{\circ}$ ). $\boldsymbol{d}$ Anteroposterior radiograph of the same patient 10 years postoperatively with progressive subsidence, stem migration (malalignment - varisation to $16^{\circ}$ ). The radiolucent line is around the whole stem, without bony trabecular development. There is a hypertrophy of the lateral femoral cortex. Patient has thigh pain, but is able to walk without crutches, and refused revision surgery. $\boldsymbol{e}$ Axial radiograph of the same patient, radiolucent lines are visible around the whole stem. This Proxima is loose radiographically.

In the second stem (neutral position after implantation) we found migration - varisation to $10^{\circ}$ with subsidence to $2 \mathrm{~mm}$ by the sixth postoperative month. There was no loosening, or thigh pain, at the next observation. This stem was osseously stable at the last visit.

In the third such stem (in neutral position postoperatively) we found slow progression of migration 
(varisation to $16^{\circ}$ ) and subsidence more than $2 \mathrm{~mm}$. This stem was loose, with radiolucent lines around the whole stem in both projections, and with thigh pain (fig. 3a-e).

Stem fixation, using the criteria of Engh et al., was osseously stable in 16 hips (94.1\%) and loose in one above-mentioned stem (5.9\%).

Stress shielding grade I, according to Zicat et al. in modified Gruen zone 7, was found in 11 stems (64.7\%); this phenomenon was not found in the one loose stem, in the one stem with infection and in the last four implanted stems at the last visit.

Heterotopic ossification was diagnosed in five hips $(29.4 \%)$ - Brooker type I was found in four patients and type III in one.

Bony trabecular development was found in 15 patients $(88.2 \%)$ in modified Gruen zones 2,4,6 (fig. 2c). In two patients (with loose and infected stems), we did not find this phenomenon.

Osteolysis was diagnosed in one hip (5.9\%), with a loose stem.

We found complications in a total of three patients with a Proxima stem (17.6\%), with one stem requiring revision $(5.9 \%)$.

One THA dislocated on the third postoperative day, and was treated by closed reduction, without any further problems during the follow-up period.

One patient had infection, treated succesfully by explantation (30 months after the surgery) and reimplantation at a second stage.

One patient had slowy progressive subsidence and loosening of the stem with thigh pain $(5.9 \%)$, but he refused revision during his last visit (10 years after the implantation), (fig. 3d-e).

Kaplan-Meier survival analysis indicated an excellent clinical survival rate of $94.1 \%$, with a radiological survival rate was of $88.2 \%$ (graph 2 ).

Only one patient (after a septic hip revision) remains dissatisfied.

\section{DISCUSSION}

Displaced intracapsular femoral neck fractures should be treated with arthroplasty in patients older than 70 years, and in the age group 60-70 years THA is expected to give a better outcome than osteosynthesis. The main treatment option in

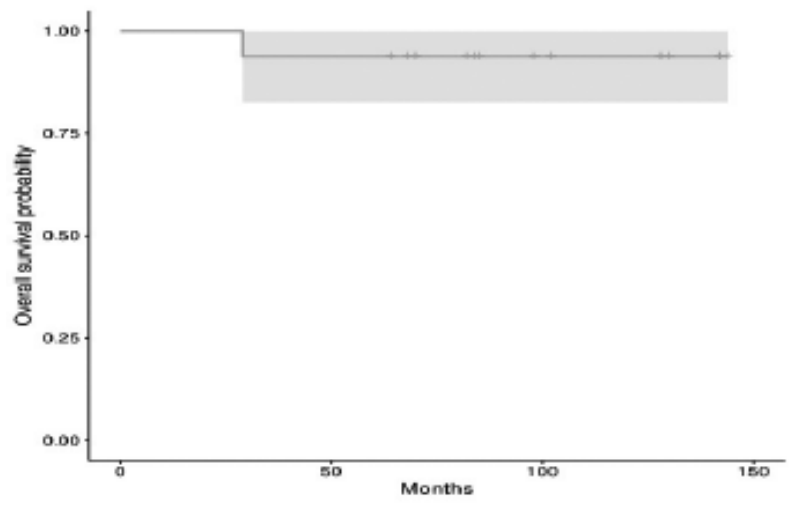

Graph 2. - Kaplan- Meier survivorship.

patients younger than 60 years is internal fixation (21). This procedure had a relative high risk of complication, with a failure rate of $44.1-59 \%$, which may lead to revision surgery with the need for THA implantation at a second stage, which could carry a higher risk than primary THA. Specific young patients (with risk factors) are candidates for primary THA. THA might also be necessary, if the fracture cannot be perfectly reduced (10). This was the case of one of our patients (no. 9, 27 years old), who had only one risk factor (femoral neck comminution) and was operated on by 6 hours after the injury. We chose primary osteosynthesis in this case, but we could not achieve satisfactory reduction, so we then decided to perform a THA.

There is a consensus, in the literature, that the risk factors mentioned in our study are important in deciding between THA or osteosynthesis $(3,15)$.

The ultra-short stem design aims at conservation of bone and could be advantageous for young patients, with the intention to reduce the thigh pain, periprosthetic bone resorption and to preserve as much bone as possible for any further revision. This stem follows the biomechanical theory of a proximal femoral force transmission into the metaphysis as well as in the region of the calcar. This requires a closed bony femoral neck ring (,high“ neck resection) with a high bone quality. After bony integration (confirmed with visible bony trabecular development on the X-ray), the apex of the stem does not transfer significantly higher forces to the diaphysis. We first decided to use 
Proxima stems in degenerative hips, and after the learning curve (especially focused on the ,round the corner technique") we started to use this implant also in traumatised hips. In these specific cases we have only equalised the femoral neck to achieve „high“ resection. We were afraid of perioperative periprosthetic fractures, stem undersizing, malalignment and version problems. In a series of trauma hips treated with the Proxima stem we did not record any perioperative periprosthetic fracture, possible undersizing was observed in one loose stem. In the one early luxation the stem version was correct.

The use of ultra-short cementless stems in primary THA for acute DIFNF is very rarely described. The incidence of DIFNF as indication for primary THA was of $4.6 \%$ (six cases of 130) in our previous study about the Proxima stem (18). From the total of 390 Proxima stems implanted in our hospital, the diagnosis of DIFNF was in 17 cases (4.4\%).

Kim et al. published the study of the group of young patients with a 324 Proxima stems. Nine Proxima stems (2.8\%) were implanted for DIFNF. Preoperative HHS of the whole group was 37 and postoperative was 93. Three patients had thigh pain $(1.3 \%)$ due to aseptic stem loosening. Stress shielding grade I was found in the area of the calcar femoris (modified Gruen zone 7). Nineteen stems $(6 \%)$ were implanted in a varus position. The incidence of superficial infection was of $0.9 \%$. The survival rate was $99.1 \%$ at 15.6 years (13). In the other study, focused on younger patients (average age 49.8 years) with the osteonecrosis of the femoral head, the same author presented the results of 335 hips with Proxima stems with a mean follow-up 14.7 years. The final average HHS was 94 points. Survivorship of the femoral stem was $99.0 \%$. (14). In the another study, they analyzed conventional and ultra-short stems and found that the incidence of some complications was significantly higher in the conventional stem group of patients with fracture of the femoral neck, and that osteointegration was obtained in both groups (12).

Gombar et al. presented results of 86 hips with the Proxima stem in patients with an average age of 50 years. The incidence of a post-traumatic diagnosis was of $4 \%$. HHS improved from 40 to 91 on average at the final evaluation. They had three
(3.5\%) periprosthetic fractures, with the need for revision in one. Stem malalignment was observed in 10 hips $(12 \%)$. Stem subsidence with osteolysis was observed in one case with undersizing. The stem survival was of $97 \%$ after 7 years (7).

Santori et al. evaluated results of 129 custommade ultra-short cementless stems with a lateral flare without diaphyseal fixation with the mean follow-up of 8 years. The mean age of patients was 51 years. The average final HHS was 95, with a survivorship of the femoral stem of $100 \%$. Bony trabecular development was visible on the final X-rays in modified Gruen zones 2 and 4 (22).

Morrey et al. reported results of 162 THA using uncemented, conservative double-tapered Mayo stems with a mean follow-up of 6.2 years. The mean age of patients was 50.8 years. The final average HHS was 90.4, with the survivorship of the stem of $98.2 \%$. Bony trabecular development was detected in Gruen zones 3 and 6 (19).

Mahmoud et al. have described a stable migration pattern (slight subsidence and varisation of the Proxima stem) without loosening, or any other problems (16). We have found this phenomenon in two of our patients, without any further problems. The migration ceased to progress after the sixth postoperative month.

The HHS in our group was very low preoperatively (6.3 points) because the patient with DIFNF is obviously unable to walk and relatively lower (82.9 points on average) at final follow-up. It is generally recognised, that traumatic hips have worse results compared to primary THA in osteoarthritis (25).

An infection rate of $5.9 \%$ in our study is a rather high percentage, but the infection of an arthroplasty is far more dramatic than infection of an osteosynthesis (9).

One patient with a loose stem remained relatively satisfied. When we retrospectively analysed this case, we found a few possible factors for stem failure: undersizing (we used size 7), poor bone quality, early full weightbearing, or low-grade infection.

Our clinical survival rate is $94.1 \%$ at a minimum of 5 years postoperatively.

Dogger et al. found, that uncemented total hip arthroplasty could be a viable option for patients 
with DIFNF with implant survival to $99.1 \%$ over five years of follow-up (4).

The re-revision rate for patients who had undergone a revision THA after failed osteosynthesis was three times higher than the rate of revision after a primary THA. THA became cost-effective in patients after the age of 44 years with multiple comorbidities (24).

Our study has some limitations. First, the study was retrospective in design, not randomized and used no control group, without which it is not possible to draw any direct conclusion on the performance of the implant in question, relative to any other. Second, we did not use radiostereometric analysis to evaluate the stem migration.

The strength of the study lies in the length of follow-up, and no patient was lost.

\section{CONCLUSION}

The exact patient age at which transition occurs from osteosynthesis to total hip arthroplasty for displaced intracapsular femoral neck fractures has not been clearly defined. Both treatment options have potential impact for younger patients. Osteosynthesis may lead to complications, requiring revision surgery, or secondary arthroplasty. A primary THA in a young patient may have to be revised within the patient's lifetime. Our results indicate, that THA with ultra-short stem in younger patient with DIFNF is a viable treatment option after individual assessment of each patient with an average clinical survival rate of $94.1 \%$.

\section{REFERENCES}

1. Brooker AF, Bowerman JW, Robinson RA, Riley LH Jr. Ectopic ossification following total hip replacement: incidence and a method of classification. J Bone Joint Surg Am. 1973 ; 55(8) : 1629-1632.

2. Cohen J. Statistical power analysis for the behavioral sciences ( $2^{\text {nd }}$ ed.). Hillsdale, NJ , Lawrence Erlbaum, 1988.

3. Dargan DP, Callachand F, Diamond OJ, Conolly, CK. Three-year outcomes of intracapsular femoral neck fractures fixed with sliding hip screws in adults aged under sixty-five years. Injury. 2016; 47(11) : 2495-2500.

4. Dogger MN, Fransen BL, Sierevelt IN, Nolte PA. Implant survival in uncemented total hip arthroplasty for displaced intracapsular femoral neck fractures: outcomes of 115 patients in a single center. Eur J Orthop Surg Traumatol. 2020; 30(5) : 885-893.
5. Engh CA, Massin P, Suthers KE. Roentgenographic assessment of the biologic fixation of porous-surfaced femoral components. Clin Orthop Relat Res. 1990; 257: 107-128.

6. Garden RS. Low-angle fixation in fractures of the femoral neck. J Bone Joint Surg Br. 1961; 43(4) : 647-663.

7. Gombar C, Janositz G, Friebert G, Sisak K. The DePuy Proxima $^{\mathrm{TM}}$ short stem for total hip arthroplasty: excellent outcome at a minimum of 7 years. J Orthop Surg. 2019; 27(2) :1-6.

8. Harris WH. Traumatic arthritis of the hip after dislocation and acetabular fractures treatment by mold arthroplasty: an end-result study using a new method of result evaluation. J Bone Joint Surg Am. 1969; 51(4): 737-755.

9. Hrubina M, Skotak M, Behounek J sr. DHS osteosynthesis for proximal femoral fractures: infectious complications. Acta Chir orthop Traum Czech. 2013; 80(5) : 351-355.

10. Chang ChH, Tsai SW, Wu PK, et. al. Suboptimal outcomes after internal fixation for displaced intracapsular femoral neck fractures in 50- to 60-years old patients. Hip Int. 2020; 30(4) : 474-480.

11. Kellgren JH, Lawrence JS. Radiological assessment of osteo-arthrosis. Ann Rheum Dis. 1957; 16(4) : 494-502.

12. Kim YH, Oh JH. A comparison of a conventional versus a short, anatomical metaphyseal-fitting cementless femoral stem in the treatment of patients with a fracture of the femoral neck. J Bone Joint Surg Br. 2012; 94(6) : 774-781.

13. Kim YH, Park JW. Long-term outcomes of ultra-short metaphyseal-fitting anatomic cementless femoral stem in total hip arthroplasty with ceramic-on-ceramic articulation for young patients. J Arthroplasty. 2019; 34(10) : 24272433.

14. Kim YH, Park JW. Ultra-short anatomic uncemented femoral stem and ceramic-on-ceramic bearing in patients with idiopathic or ethanol-induced femoral head osteonecrosis. J Arthroplasty. 2020; 35(1): 212-218.

15. Levack AE, Gausden EB, Dvorzhinskiy A, Lohrich DG, Helfet DL. Novel treatment options for the surgical management of young femoral neck fractures. J Orthop Trauma. 2019; 33(Suppl. 1): S33-S37.

16. Mahmoud AN, Kesteris U, Flivik G. Stable migration pattern of an ultra-short anatomical uncemented hip stem:a prospective study with 2 years radiostereometric analysis follow-up. Hip Int. 2017; 27(3): 259-266.

17. Martell JM, Pierson RH, Jacobs JJ, Rosenberg AG, Maley M, Galante JO. Primary total hip reconstruction with a titanium fiber-coated prosthesis inserted without cement. J Bone Joint Surg Am. 1993; 75(4) : 554-571.

18. Melisik M, Hrubina M, Hert J, Cibula Z, Cabala J, Necas L. Mid-term results Proxima ultra-short anatomical stem - analysis of 130 cases. Acta Chir orthop Traum Czech. 2021; 88(1) : 50-57.

19. Morrey BF, Adams RA, Kessler M. A conservative femoral replacement for total hip arthroplasty. A prospective study. J Bone Joint Surg B. 2000; 82(7) : 952-958. 
20. Rawall S, Bali K, Upendra B, Garg B, Yadav CS, Jayaswal A. Displaced femoral neck fractures in the young: significance of posterior comminution and raised intracapsular pressure. Arch Orthop Trauma Surg. 2012; 132(1): 73-79.

21. Rogmark C, Kristensen MT, Viberg B, Rönnquist SS, Overgaard S, Palm H. Hip fractures in the non-elderly who, why and whiter? Injury. 2018; 49(8): 1445-1450.

22. Santori FS, Santori N. Mid-term results of a custom-made short proximal loading femoral component. J Bone Joint Surg Br. 2010; 92(9) :1231-1237.

23. Slobogean GP, Sprague SA, Scott T, Bhandari M. Complications following young femoral neck fractures. Injury. 2015; 46(3) : 484-491.

24. Swart E, Roulette P, Leas D, Bozic KJ, Karunakar M. ORIF or arthroplasty for displaced femoral neck fractures in patients younger than 65 years old. J Bone Joint Surg Am. 2017; 99(1) : 65-75.

25. Talboys R, Pickup L, Chojnowski A. The management of intracapsular hip fractures in the "young elderly" internal fixation or total hip replacement? Acta Orthop Belg. 2012; 78(1) : 41-48.

26. Toth K, Mecs L, Kellermann P. Early experience with the DePuy Proxima ${ }^{\mathrm{TM}}$ short stem in total hip arthroplasty. Acta Orthop Belg. 2010; 76(5): 613-618.

27. Upadhyay A, Jain P, Mishra P, Maini L, Gautum VK, Dhaon BK. Delayed internal fixation of fractures of the neck of the femur in young adults. J Bone Joint Surg Br. 2004; 86(7) : 1035-1040.

28. Zicat B, Engh CA, Gokcen E. Patterns of osteolysis around total hip components inserted with and without cement. J Bone Joint Surg Am. 1995; 77(3): 432-439. 